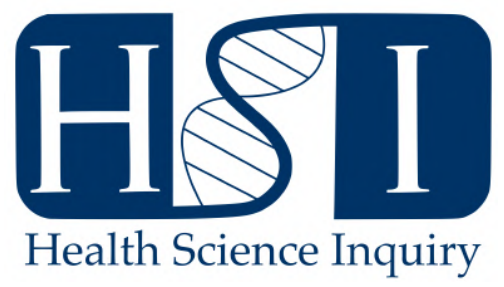

\title{
Social media: A Growing Presence in Healthcare
}

\author{
Sharon Ling ${ }^{1}$ \\ ${ }^{1}$ Department of Immunology, Faculty of Medicine, University of Toronto
}

\section{INTRODUCTION}

The words friends, follow, and snap no longer mean what they did 15 years ago. Since the launch of Facebook in 2004, Instagram in 2010 and Snapchat in 2011, social media (SM) platforms have radically changed the ways in which people interact and communicate. With an estimated 2.62 billion SM users globally, many are bringing discussions into the online world and the healthcare industry is no exception [1]. However, what may seem as an attractive avenue for fostering networks, educating patients, and promoting public awareness, may simultaneously pose complex questions regarding privacy, accuracy of information, and professionalism.

\section{Potential APPlications in HeAlthCARE}

Healthcare providers (HCPs) are continually looking to improve communication, both with each other and their patients. Accessible, instantaneous, and intrinsic to the daily routines of billions - SM offers the possibility of doing just that. Within the field of medicine, one of the most valuable moments of communication can be found in patient education. Well-educated patients are better able to inquire about, understand, and manage their conditions which can ultimately improve patient outcomes [2]. One of the most well-known healthcare figures in SM that promotes patient education is Dr. Mikhail Varshavski. Known online as Doctor Mike, he provides daily posts on his day-to-day tasks as a physician as well as tips on having a healthy and active lifestyle - he currently has 3 million followers on Instagram.

SM may extend the patient-HCP relationship beyond the clinic and help keep patients informed between visits. It has been suggested that platforms like Facebook Groups could be used to circulate general information such as suggestions on blood pressure maintenance, preparing for procedures (e.g., fasting prior to imaging procedures), and when seasonal vaccines are offered [3]. With the rapid expansion of SM, patients are also expressing interest in using online platforms to communicate with their providers. In fact, $56.4 \%$ of patients surveyed in an outpatient family clinic responded favourably to receiving diagnostic results and appointment updates via SM [4].

Healthcare institutions are also recognizing the power of SM in marketing, attracting the public's attentions, and promoting awareness [5]. In 2017, the largest hospital fundraising campaign in Canadian history was launched-the SickKids VS Limits Campaign-during which Toronto's Hospital for Sick Children (SickKids) set out to raise $\$ 1.3$ billion in hopes of updating medical equipment and technology [6]. To spread their message, the hospital designed videos and advertisements that can be viewed across YouTube, Facebook, and their own campaign website. Gaining exposure online was critical to the success of the campaign, considering, between 2010 and 2017, the average amount of time Canadians spent online rose from 13.4 to 21.8 hours per week [7].

\section{ImPORTANT IMPLICATIONS TO CONSIDER}

In attempts to strengthen patient-HCP relationships and raise awareness, increased employment of SM may also bring deliberations on appropriate use and professionalism. While some physicians support connecting with patients online, others are concerned with the dangers of crossing professional boundaries [5]. It is uncertain as to whether SM could significantly improve patient outcomes yet, but it has become such an integral part of society that hospitals and other healthcare institutions have developed guidelines discussing the gravity of preserving patient confidentiality and privacy. Furthermore, the Canadian Medical Association (CMA) currently has a published policy that examines social media risks, benefits, as well as rules of engagement for Canadian physicians [8]. As SM use in the clinic grows, additional efforts to be conscientious and more specific guidelines will be required to help HCPs uphold the ethical and professional values that are central to providing quality healthcare.

It is also vital to consider the mounting availability of patient data, dissemination of unfounded medical advice, and its implications on patient behaviour. According to the American Osteopathic Association (AOA), it was found that $32 \%$ of Americans between the ages of 18 to 34 have applied a health-related action based on information acquired on SM [9]. Moreover, $15 \%$ of parents with children under 18 have self-diagnosed a condition based on social media postings [9]. Though social media has the ability to assist patients in making health-related decisions, HCPs will need to be conscious of where patients are sourcing their information from and encouraging them to examine online content with a more critical eye. This will serve not only to aid patients in asking the right questions regarding 
their conditions but also, more importantly, to help keep patients safe when it comes to selecting treatment options.

\section{Conclusion}

If used prudently, SM and online platforms offer promising mediums for HCPs to enhance their connections with patients. However, the implementation of such a powerful tool will need to be monitored and managed. It is likely that SM will remain and grow for many years to come and for the field of healthcare and medicine, it brings both a unique set of opportunities and challenges.

\section{REFERENCES}

[1] Statista. Number of social media users worldwide from 2010 to 2021 (in billions);. Available from: https://www.statista.com/statistics/278414/ number-of-worldwide-social-network-users.

[2] Marcus C. Strategies for improving the quality of verbal patient and family education: a review of the literature and creation of the EDUCATE model. Health Psychology and Behavioral Medicine: An Open Access Journal. 2014;2(1):482-495.

[3] George DR, Rovniak LS, Kraschnewski JL. Dangers and opportunities for social media in medicine. Clinical obstetrics and gynecology. 2013;56(3).

[4] Fisher J, Clayton M. Who gives a tweet: assessing patients' interest in the use of social media for health care.
Worldviews on Evidence-Based Nursing. 2012;9(2):100108.

[5] Chretien KC, Kind T. Social media and clinical care: ethical, professional, and social implications. Circulation. 2013;127(13):1413-1421.

[6] CTVNews. SickKids hospital rallying 'crews' around \$1.3-billion fundraising drive.;. Available from: https://www.ctvnews.ca/canada/sickkidshospital-rallying-crews-around-1-3-billionfundraising-drive-1.4126468.

[7] Statista. Average weekly time spent online in Canada from 2010 to 2017 (in hours).;. Available from: https://www.statista.com/statistics/ 473730/canada-weekly-time-spent-online/.

[8] Canadian Medical Association. Social media and Canadian physicians: Issues and rules of engagement.; Available from: http://policybase.cma.ca/dbtwwpd/Policypdf/PD12-03.pdf.

[9] American Osteopathic Association. Survey Finds Patients Want to be Friends with their Physicians on Social Media.;. Available from: https://osteopathic.org/2018/05/14/surveyfinds-patients-want-to-be-friends-with-theirphysicians-on-social-media/.

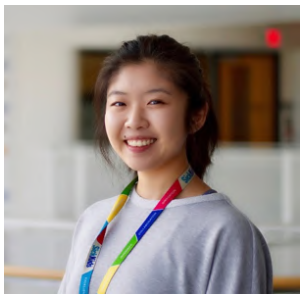

Sharon Ling completed her BMSc, specializing in microbiology and immunology, at the University of Western Ontario. She is currently an MSc candidate in the Department of Immunology at the University of Toronto. Under the supervision of Dr. Rae Yeung at SickKids, she is investigating the role of circulating DNA (cDNA) and mitochondrial DNA in the pathogenesis of Kawasaki Disease. 